\title{
Restructuring Early Transition Metal Oxide for New Catalysis
}

\author{
Franklin (Feng) Tao ${ }^{1}$, Shiran Zhang ${ }^{1}$, Yuan Zhu ${ }^{1}$, Hideto Yoshida ${ }^{2}$, Seiji Takeda ${ }^{2}$ \\ ${ }^{1}$ Department of Chemistry and Biochemistry, University of Notre Dame, Notre Dame, Indiana, \\ 46556, USA \\ ${ }^{2}$ Institute of Scientific and Industrial Research, Osaka University, 8-1 Mihogaoka, Ibaraki, Osaka \\ 567-0047, Japan
}

Early transition metal oxide is one main category of heterogeneous catalysts. Most of them are reducible oxides. Oxygen vacancies can be generated on surface or bulk in gaseous environment. Even a phase transformation could be performed under the reaction condition of catalysis. Both processes could happen to an early transition metal oxide during catalysis. Removal of poisonous gases, including nitric oxide and carbon monoxide, released from vehicle engines and chemical industries is critical toward a sustainable environment. The search for cost-effective catalysts without any non-precious metals highly selective and active in reduction of nitric oxide to nitrogen $\left(\mathrm{N}_{2}\right)$ has remained a significant challenge. We successfully developed a new catalyst through restructuring of a pure early transition metal oxide. Non-stoichiometric cobalt monoxide is formed from as-synthesized $\mathrm{Co}_{3} \mathrm{O}_{4}$ nanorods under reaction conditions. Rock-salt $\mathrm{CoO}_{1-\mathrm{x}}$ exhibits distinctly different catalytic performance in contrast to the original $\mathrm{Co}_{3} \mathrm{O}_{4}$ of spinel phase. The active phase was identified with advanced in-situ micro analytical techniques including environmental TEM (E-TEM) and ambient pressure X-ray photoelectron spectroscopy (AP-XPS).

As shown in Figure 1 diffraction pattern of $\mathrm{Co}_{3} \mathrm{O}_{4}$ is transformed to $\mathrm{CoO}$ at a temperature of $250-300^{\circ} \mathrm{C}$ in an environment of $\mathrm{CO}$. This is consistent with in-situ EELS spectra under the same reaction condition. These studies showed a transformation of bulk phase from $\mathrm{Co}_{3} \mathrm{O}_{4}$ to $\mathrm{CoO}$. Evolution of surface phase under catalytic conditions (a mixture of two reactants $\mathrm{CO}$ and NO) was tracked with ambient pressure XPS. Figure $2 \mathrm{a}$ presents the photoemission feature of Co $2 \mathrm{p}$ and $\mathrm{O} 1 \mathrm{~s}$ of the catalyst at different reaction temperatures. Photoemission features of Co $2 \mathrm{p} 3 / 2$ and $\mathrm{Co} 2 \mathrm{p} 1 / 2$ of $\mathrm{Co}_{3} \mathrm{O}_{4}$ nanorods were identified at $779.8 \mathrm{eV}$ and $795.1 \mathrm{eV}$, consistent with those of $\mathrm{Co}_{3} \mathrm{O}_{4}$ nanoparticles and single crystals. $\mathrm{CoO}$ is formed from $\mathrm{Co}_{3} \mathrm{O}_{4}$ in reactant gases during catalysis. AP-XPS studies showed the $\mathrm{Co}_{3} \mathrm{O}_{4}$ is partially reduced to $\mathrm{CoO}$ at $250^{\circ} \mathrm{C}$ in a mixture of $\mathrm{CO}$ and $\mathrm{NO}$ with a ratio of partial pressures of $3: 1$. The reduction of $\mathrm{Co}_{3} \mathrm{O}_{4}$ to $\mathrm{CoO}$ is evident by the appearance of satellite peaks marked in Figure 2a9. The satellite peaks of $\mathrm{Co} 2 \mathrm{p}$ of $\mathrm{CoO}$ were identified at $786.4 \mathrm{eV}$ and $803.0 \mathrm{eV}$ for Co $2 \mathrm{p}_{3 / 2}$ and $\mathrm{Co}$ $2 \mathrm{p}_{1 / 2}$, respectively, which are $\sim 5.9 \mathrm{eV}$ and $\sim 6.7 \mathrm{eV}$ higher than the corresponding main photoemission features at $\sim 780.5 \mathrm{eV}$ and $\sim 796.3 \mathrm{eV}$. At $400^{\circ} \mathrm{C}-500^{\circ} \mathrm{C}, \mathrm{Co}_{3} \mathrm{O}_{4}$ is completely reduced to $\mathrm{CoO}$ in $\mathrm{CO}+\mathrm{NO}$ and no photoemission feature of metallic cobalt is observed.

The in-situ formed $\mathrm{CoO}$ catalyst is highly active for reducing $\mathrm{NO}$ with $\mathrm{CO}$. Catalytic measurements showed the evolution of catalytic selectivity in the production of $\mathrm{N}_{2}$ as a function of reaction temperature (Figure $2 \mathrm{~b}$ ). At $110^{\circ} \mathrm{C}, \mathrm{Co}_{3} \mathrm{O}_{4}$ exhibits a detectable conversion of $\mathrm{NO}(17 \%)$, but only $\mathrm{N}_{2} \mathrm{O}$ is produced. The conversion of $\mathrm{NO}$ at $150^{\circ} \mathrm{C}$ is $85 \%$ with an $\mathrm{N}_{2}$ selectivity of $9.0 \%$; at $170^{\circ} \mathrm{C}$ the conversion of $\mathrm{NO}$ reaches $100 \%$. Selectivity to production of $\mathrm{N}_{2}$ increases progressively in the temperature regime of $170^{\circ} \mathrm{C}-420^{\circ} \mathrm{C}$ and reaches $100 \%$ at $420^{\circ} \mathrm{C}$, followed by maintaining the $100 \%$ selectivity through $480^{\circ} \mathrm{C}$. Upon measurements at $480^{\circ} \mathrm{C}$, the catalyst was cooled down to $300^{\circ} \mathrm{C}$ and then $250^{\circ} \mathrm{C}$; AP-XPS studies showed the surface of the catalyst still remains at the chemical state of $\mathrm{CoO}$ at $250^{\circ} \mathrm{C}$ under this reaction conditions (Figure 2a16). Selectivity to $\mathrm{N}_{2}$ at $300^{\circ} \mathrm{C}$ and $250^{\circ} \mathrm{C}$ is $100 \%$ (Figure $2 \mathrm{~b}$ ). The turn-over-frequency (TOF) of $\mathrm{N}_{2}$ production at $420^{\circ} \mathrm{C}$ is $1.55 \mathrm{~N}_{2}$ molecules per 
cobalt atom per second, higher than $0.08-0.27$ of $\mathrm{Rh}$ nanocatalysts. It is stable up to 36 hours at $420^{\circ} \mathrm{C}$ without any loss of activity and selectivity (100\%). At $48^{\text {th }}$ hour, selectivity to the production of $\mathrm{N}_{2}$ is decreased to $95 \%$ though high activity still remains. In-situ studies revealed that the active phase is nonstoichiometric $\mathrm{CoO}$. This work demonstrated that restructuring of early transition metal oxide can be used for development of catalysts.
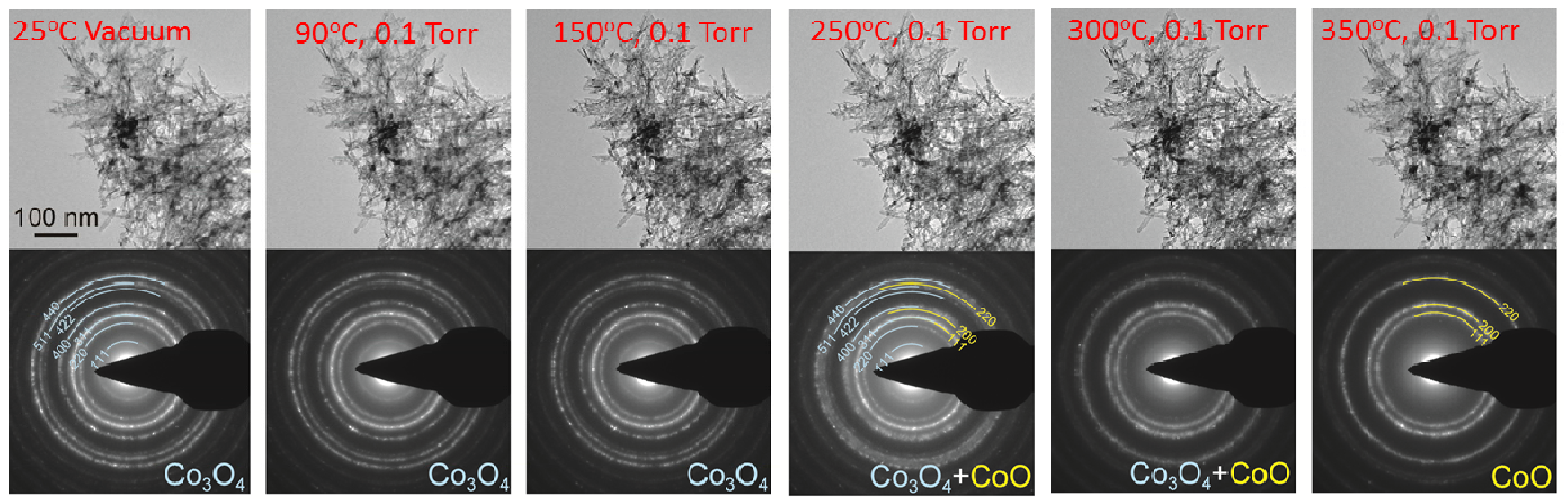

Figure 1. Diffraction patterns of as-synthesized $\mathrm{Co}_{3} \mathrm{O}_{4}$ under reaction conditions at different temperature. Images were collected with E-TEM when the catalyst was in gaseous environment.

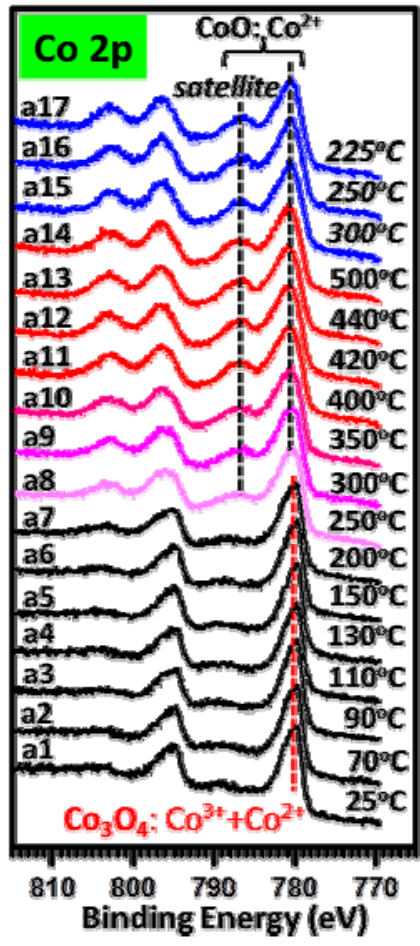

(a)

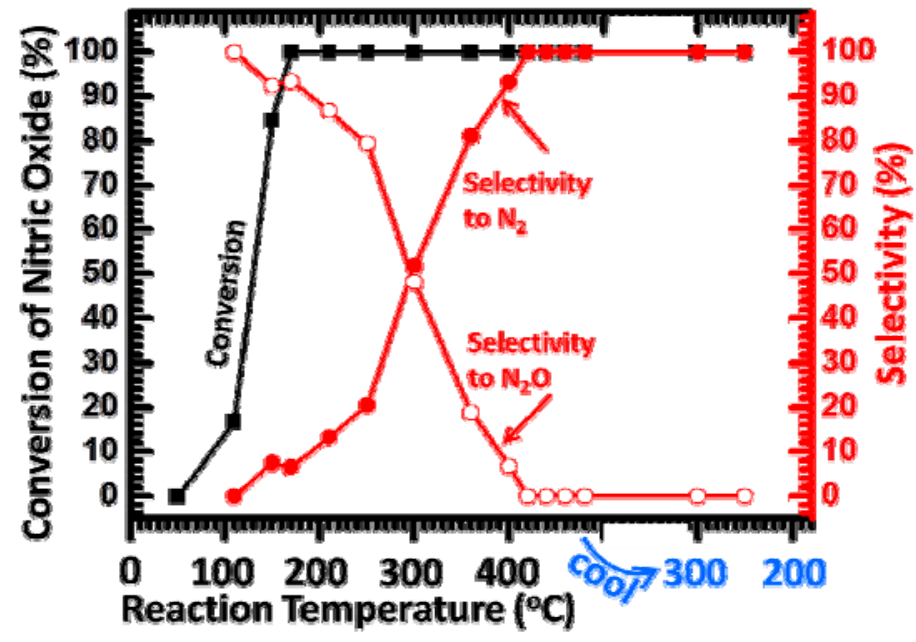

(b)

Figure 2. In-situ surface chemistry of the catalyst and the corresponding catalytic performance at different temperatures. (a) Co $2 p$ photoemission feature of catalysts during catalysis in 3 Torr $\mathrm{CO}$ and 1 Torr NO studies with AP-XPS. (b) Catalytic activity (left axis) and selectivity (right axis) as a function of reaction temperature. 